\title{
Hydrogen adsorption capacity using modified nickel-kenaf core at different concentrations
}

\author{
S. N. Ezaty ${ }^{1}$, N. Zaini ${ }^{1}$, N. J. Farahhin ${ }^{2}$, and K. S. N. Kamarudin ${ }^{2}$ \\ ${ }^{1}$ Malaysia-Japan International Institute of Technology, Universiti Teknologi Malaysia, Jalan Sultan \\ Yahya Petra, 54100 Kuala Lumpur, Malaysia. \\ ${ }^{2}$ School of Chemical and Energy Engineering, Faculty of Engineering, Universiti Teknologi Malaysia, \\ 81310 Johor Bahru, Johor, Malaysia.
}

\begin{abstract}
In this study, surface chemistry modification of kenaf adsorbent in adsorptive hydrogen storage system was computationally investigated using Brunauer-Emmett-Teller (BET) surface area, thermogravimetric analysis (TGA), field emission scanning electron microscopy (FESEM), and elemental dispersion X-ray (EDX) analysis, in which the suitability of the adsorbent was determined with detailed physicochemical characterisation analysis. The method used for surface modification was metal deposition method using $\mathrm{Ni}\left(\mathrm{NO}_{3}\right)_{2}$ with various concentrations at different levels of pressure (up to 6 bars). Based on this research, modified kenaf with $0.4 \mathrm{M}$ $\mathrm{Ni}\left(\mathrm{NO}_{3}\right)_{2}$ and $2.559 \mathrm{~m}^{2} \mathrm{~g}^{-1}$ adsorbed up to $1.013 \mathrm{mmol} \mathrm{g}$ of hydrogen compared to the raw kenaf with only $0.396 \mathrm{mmol} \mathrm{g}^{-1}$ of hydrogen adsorbed in $5 \mathrm{~h}$. Two consecutive cycles of adsorption were carried out to show the delivery performance of hydrogen adsorptive storage. Thus, different adsorption ability between the modified kenaf and raw kenaf shows that Nimetal on kenaf surface assists in hydrogen adsorption process.
\end{abstract}

\section{Introduction}

At present, adsorptive hydrogen storage using porous materials becomes an alternative method for hydrogen-fuelled vehicles. Adsorptive processes usually require highly porous materials to obtain maximum surface area available for hydrogen sorption. It also requires easy uptake and release of hydrogen from the materials. By using a suitable adsorbent, hydrogen gas can be adsorbed and stored efficiently compared to the pressurised gas and cryogenic techniques currently used in fuel technology, which are costly and require large space and pressure [1].

There are several adsorbents for hydrogen adsorption that have been investigated since 1960s such as activated carbons, carbon aerogels, zeolites, Zn-based MOFs, Cu-based MOFs, Mn-based MOFs, and Ni-based MOFs [2, 3, 4]. However, current commercial adsorbents are unsuitable for hydrogen adsorption due to flammable hydrogen characteristics and heavy weight of the adsorbent itself. High moisture content in an adsorbent could be an initiator for explosion to occur. Current research focuses on finding an ideal adsorbent that is lightweight, can be used at room temperature, and allows the storage of a desirable amount of hydrogen 
with high adsorption and desorption performance.

In this research, the use of kenaf (Hibiscus cannabinus L.) as a bioadsorbent is the main concern for investigation since it is considered to be lightweight, less harmful, more approachable towards the environment, works well under a wide range of temperatures and humidity levels, inert, safe to handle, easily accessible, cost-effective, has porous structure, and high affinity towards organic molecules, mainly solvents and chemicals [5]. Additionally, the motivation and incentives given by the government to intensify the use of kenaf in Malaysia are in line with the demands for a natural adsorbent originated from agrobased material. By considering kenaf adsorbent as a gas adsorption material, hydrogen storage may improve for filling and delivering due to its light weight and high surface area [6].

The characteristics of an adsorbent influence the performance of adsorption process. The reaction of an adsorbent and its behaviour with hydrogen molecules depends on its surface modification. Two types of adsorption are physical and chemical adsorption. In physical adsorption of kenaf, adsorbed molecules are held on the surface of kenaf by weak Van der Waals forces with low activation energy and it is a fast adsorption process. Meanwhile, chemical adsorption can overcome certain limitations of physical adsorption such as strong chemical bonding [7]. In our research, physical adsorption of kenaf is the dominant process of hydrogen adsorption.

Since the effect of surface chemistry modification has become one of the factors required, the surface properties of kenaf in this research are modified by nickel to maximise its surface properties and improve adsorption characteristics. The investigation on hydrogen adsorption capacity using modification of nickel solution $\left(\mathrm{Ni}\left(\mathrm{NO}_{3}\right)_{2}\right)$ through impregnation process with kenaf core is a new approach. The size of kenaf core fibre (inner fibre) used for modification purpose is $500 \mu \mathrm{m}$. N. Zaini and K. S. N. Kamarudin [8] determined that kenaf with the particle size of $300-500 \mu \mathrm{m}$ has high affinity towards its adsorbates. By proper physicochemical modification, Ni-kenaf adsorbent can increase its surface properties and improve adsorption characteristics. Unfortunately, their temperature and scalability will be intractable challenges and these challenges are discussed in this paper.

\section{Experimental methods}

\subsection{Materials and methods}

\subsubsection{Raw materials and chemicals}

Raw kenaf (Hibiscus cannabinus L.) core fibre was provided by the National Kenaf and Tobacco Board (NKTB), Kelantan, Malaysia. The chemicals used for modification of kenaf were nickel nitrate $\left(\mathrm{Ni}\left(\mathrm{NO}_{3}\right)_{2}\right)$ and sodium hydroxide $(\mathrm{NaOH})$ solution in nickel metal deposition method. Formaldehyde (HCHO) was used to completely reduce the metal precursor, whereas ethanol $\left(\mathrm{C}_{2} \mathrm{H}_{6} \mathrm{O}\right)$ was used for metal dispersion on kenaf surface. Purified hydrogen gas $(99.99 \%)$ used during the adsorption process in the gas performance study was procured from MegaMount Industrial Gases Sdn. Bhd.

\subsubsection{Chemical modification}

Kenaf samples were treated with $\mathrm{Ni}\left(\mathrm{NO}_{3}\right)_{2}$ at various concentrations for $15 \mathrm{~min}$ at $45^{\circ} \mathrm{C}$ to determine the most applicable modified kenaf used to adsorb higher capacity of hydrogen gas. $\mathrm{NaOH}, \mathrm{HCHO}$, and $\mathrm{C}_{2} \mathrm{H}_{6} \mathrm{O}$ were mixed into samples and stirred for another $4 \mathrm{~h}$. Then, the samples were filtered and dried at room temperature for $10 \mathrm{~h}$. The composition of 
solutions used in metal deposition is presented in Table 1.

Table 1. Composition of solutions for metal dissolved on kenaf samples.

\begin{tabular}{|c|c|c|c|c|c|}
\hline Chemicals & $\begin{array}{c}\text { Raw } \\
\text { Kenaf }\end{array}$ & $\begin{array}{c}\text { Ken- } \\
0.03 \mathrm{MNi}\end{array}$ & $\begin{array}{c}\text { Ken- } \\
0.2 \mathrm{MNi}\end{array}$ & $\begin{array}{c}\text { Ken- } \\
0.4 \mathrm{MNi}\end{array}$ & $\begin{array}{c}\text { Ken- } \\
0.6 \mathrm{MNi}\end{array}$ \\
\hline Kenaf Core (g) & 10 & 10 & 10 & 10 & 10 \\
\hline $\mathrm{Ni}\left(\mathrm{NO}_{3}\right)_{2} 0.03 \mathrm{M}(\mathrm{ml})$ & - & 300 & - & - & - \\
\hline $\mathrm{Ni}\left(\mathrm{NO}_{3}\right)_{2} 0.2 \mathrm{M}(\mathrm{ml})$ & - & - & 190 & - & - \\
\hline $\mathrm{Ni}\left(\mathrm{NO}_{3}\right)_{2} 0.4 \mathrm{M}(\mathrm{ml})$ & - & - & - & 160 & - \\
\hline $\mathrm{Ni}\left(\mathrm{NO}_{3}\right)_{2} 0.6 \mathrm{M}(\mathrm{ml})$ & - & - & - & - & 360 \\
\hline $\left.\mathrm{NaOH}^{2} \mathrm{ml}\right)$ & - & 100 & 125 & 260 & 396 \\
\hline $\mathrm{HCHO} 37 \%(\mathrm{ml})$ & - & 30 & 30 & 60 & 96 \\
\hline $\mathrm{C}_{2} \mathrm{H}_{6} \mathrm{O}(\mathrm{ml})$ & - & 30 & 20 & 42 & \\
\hline
\end{tabular}

\subsubsection{Physical modification}

Kenaf core was ground into a smaller size, sieved, and separated to obtain $500 \mu \mathrm{m}$ of particle size. After the samples were heated and chemically modified to enhance adsorptive characteristic by using $\mathrm{Ni}\left(\mathrm{NO}_{3}\right)_{2}$, kenaf was characterised to determine the physical and structural properties of the adsorbent. Finally, the modified kenaf was tested for adsorptive hydrogen storage performance. Along with adsorptive study, the gas delivery performance study was observed by adsorption and desorption of hydrogen gas at selected pressure of 2 , 4 , and 6 bars respectively.

\subsection{Characterisation}

Raw kenaf and modified kenaf surface were characterised using Brunauer-Emmett-Teller (BET) surface area to provide information on the surface characteristics of kenaf prior to chemical impregnation and hydrogen adsorption process. A large surface area is required for hydrogen adsorption process. The modified kenaf surface area $\left(\mathrm{m}^{2} \mathrm{~g}^{-1}\right)$ was calculated by using the BET equation [9]: 


$$
\begin{aligned}
& \text { Stotal }=v \mathrm{~m} \mathrm{Ns} / \mathrm{V} \\
& \text { SBET }=\text { Stotal } / a
\end{aligned}
$$

Changes in physical and chemical properties were determined using thermogravimetric analysis (TGA) with the heating rate of $20^{\circ} \mathrm{C} \mathrm{min}^{-1}$ (30 to $900{ }^{\circ} \mathrm{C}$ ). Field emission scanning electron microscopy (FESEM) analysis was used to observe the surface morphologies by producing the images of raw and modified kenaf coated by gold to avoid any electron discharging. Finally, energy dispersive X-ray (EDX) analysis was performed to determine the elements present on the prepared samples with the assist of X-ray electron dispersion mechanism.

\subsection{Hydrogen adsorption system}

A hydrogen gas storage system was used to determine the amount of hydrogen adsorbed and the best operating conditions for adsorptive gas storage using surface modified kenaf in laboratory scale. Before conducting the test, leakage test was done in the first place to prevent any leakage throughout the lines in the system. An adsorbent reactor with the volume of 141.4 inch $^{3}$ was used to store kenaf samples for hydrogen adsorptive test. This reactor was manufactured using stainless steel type $316 \mathrm{~L}$ and fabricated without any joint attached during fabrication.

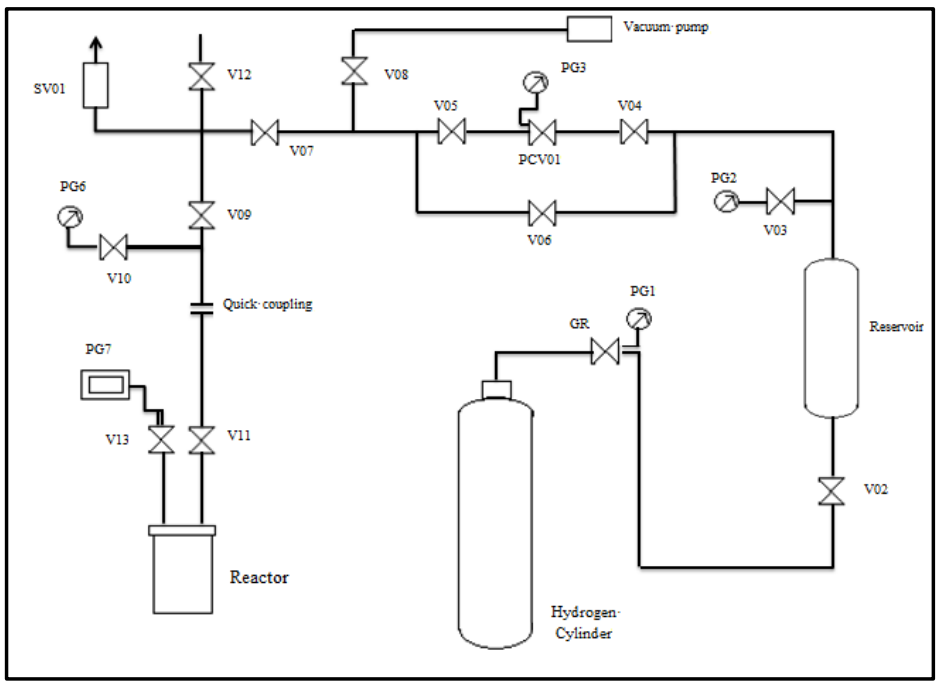

Fig. 1. System flow design.

The reactor was installed with a pressure gauge and connected to the system using 0.3 inch stainless steel tubing. Valves were installed to control hydrogen flow in the system. A digital pressure gauge was used to determine the smallest changes in the hydrogen performance study. All the pressure gauges were calibrated prior to the experiment to ensure the precision of the data collected. Table 2 shows the specifications of the adsorbent reactor. This experiment was conducted with a pressure range from 2 to 8 bars based on the design pressure, limited to the maximum pressure value of 10 bars. 
Table 2. Specifications of the adsorbent reactor.

\begin{tabular}{|c|c|}
\hline Type & Reactor \\
\hline Material & Stainless steel type 316L \\
\hline Design Pressure & 10 bar \\
\hline Design Temperature & Up to $100{ }^{\circ} \mathrm{C}$ \\
\hline Volume & 141.4 inch ${ }^{3}$ \\
\hline Dimension & $\begin{array}{c}3 \text { inch (diameter) } \times 5 \\
\text { inch (length) }\end{array}$ \\
\hline Thickness & 0.5 inch \\
\hline Product Storage & Kenaf sample \\
\hline
\end{tabular}

\section{Results and discussion}

\subsection{Characterisation}

\subsubsection{BET and GAB specific area}

Kenaf adsorbent was enhanced by nickel deposition method due to the capability of Ni-metal in adsorbing hydrogen that can encourage the delivery performance of hydrogen storage. Table 3 shows the structural properties of kenaf and modified kenaf, which are necessary to understand and determine the suitable adsorbent for maximum hydrogen storage. The Guggenheim-Anderson-de Boer (GAB) parameter determines the greater versatility of the GAB equation, which has a quite larger range of applicability than the BET isotherm [13]. The difference between the BET and GAB values is much more pronounced for the energy constant than for the monolayer capacity. 
Table 3. Structural properties of kenaf samples.

\begin{tabular}{|c|c|c|c|c|c|}
\hline Sample & $\begin{array}{c}\text { BET Surface } \\
\text { Area } \\
\left(\mathrm{m}^{2} \mathrm{~g}^{-1}\right)\end{array}$ & $\begin{array}{c}\text { Total Pore } \\
\text { Volume } \\
(\AA)\end{array}$ & $\begin{array}{c}\text { Average Pore } \\
\text { Diameter } \\
(\AA)\end{array}$ & $\begin{array}{c}\text { GAB Surface } \\
\text { Area } \\
\left(\mathrm{m}^{2} \mathrm{~g}^{-1}\right)\end{array}$ & $\begin{array}{c}\text { Volum } \\
\mathrm{e} \\
\left(\mathrm{cm}^{3} \mathrm{~g}^{-}\right. \\
\left.{ }^{2}\right)\end{array}$ \\
\hline Raw Kenaf & 0.699 & 371.68 & 65.39 & 0.726 & 0.22 \\
\hline Ken-0.03MNi & 0.864 & 504.13 & 74.73 & 1.252 & 0.38 \\
\hline Ken-0.2MNi & 1.076 & 719.58 & 79.36 & 1.303 & 0.39 \\
\hline Ken-0.4MNi & 1.315 & 927.24 & 79.99 & 2.559 & 0.77 \\
\hline Ken-0.6MNi & 1.205 & 505.93 & 70.26 & 0.648 & 0.20 \\
\hline
\end{tabular}

For this study, GAB surface areas of the adsorbents were recorded to justify the heterogeneity of adsorption rate. The GAB model has the best conformity with the experimental data and can achieve almost similar of the so-called "BET monolayer capacity" with that of the original BET equation using consistency criteria [10]. Based on Table 3, Ken$0.4 \mathrm{MNi}$ showed the highest GAB surface area with $2.559 \mathrm{~m}^{2} \mathrm{~g}^{-1}$ of adsorbent compared to other adsorbents. This is due to its uniform structural properties, which is determined as good adsorbent materials.

\subsubsection{Thermogravimetric analysis}

TGA was performed for analysing the change in physical and chemical properties of the adsorbent. In this study, each sample was heated to $900{ }^{\circ} \mathrm{C}$ with a temperature ramp of 1.85 ${ }^{\circ} \mathrm{C}$ min $^{-1}$ under a flowing nitrogen gas. Figure 2 shows raw kenaf weight loss during TGA.

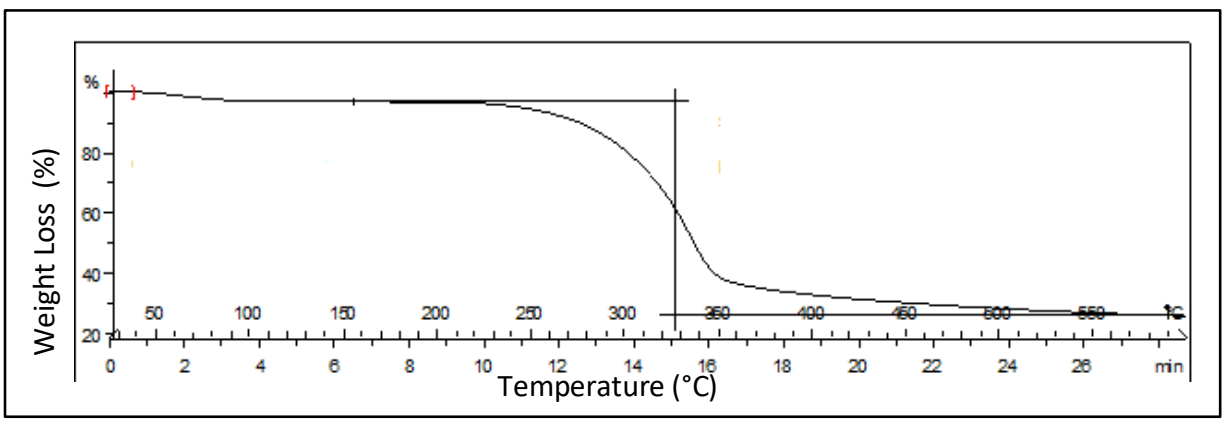

Fig. 2. Raw kenaf weight loss during heating.

Initially, moisture content was detected for kenaf sample during the first $4 \mathrm{~min}$. 
However, the moisture reduced gradually as the temperature increased until $150{ }^{\circ} \mathrm{C}$. The result showed that there was water content in raw kenaf sample. At $250{ }^{\circ} \mathrm{C}$, the mass of raw kenaf weight started to reduce until $350^{\circ} \mathrm{C}$. This is due to desorption of hydrogen molecules from kenaf pore structures, and a sudden decrease until $350{ }^{\circ} \mathrm{C}$ is due to decomposition of raw kenaf material.

\subsubsection{Field electron scanning electron microscopy}

Figure 3 shows kenaf modification with different concentrations of nickel metal. Generally, modified kenaf surface shows better surface image to adsorb more hydrogen gas [11]. It is believed that nickel increases the active sites on adsorbent surface for the highest hydrogen storage capacity. Figures 3(a) and 4(b) show the surfaces of kenaf modified with $0.03 \mathrm{M}$ and $0.2 \mathrm{M}$ nickel metal, respectively.
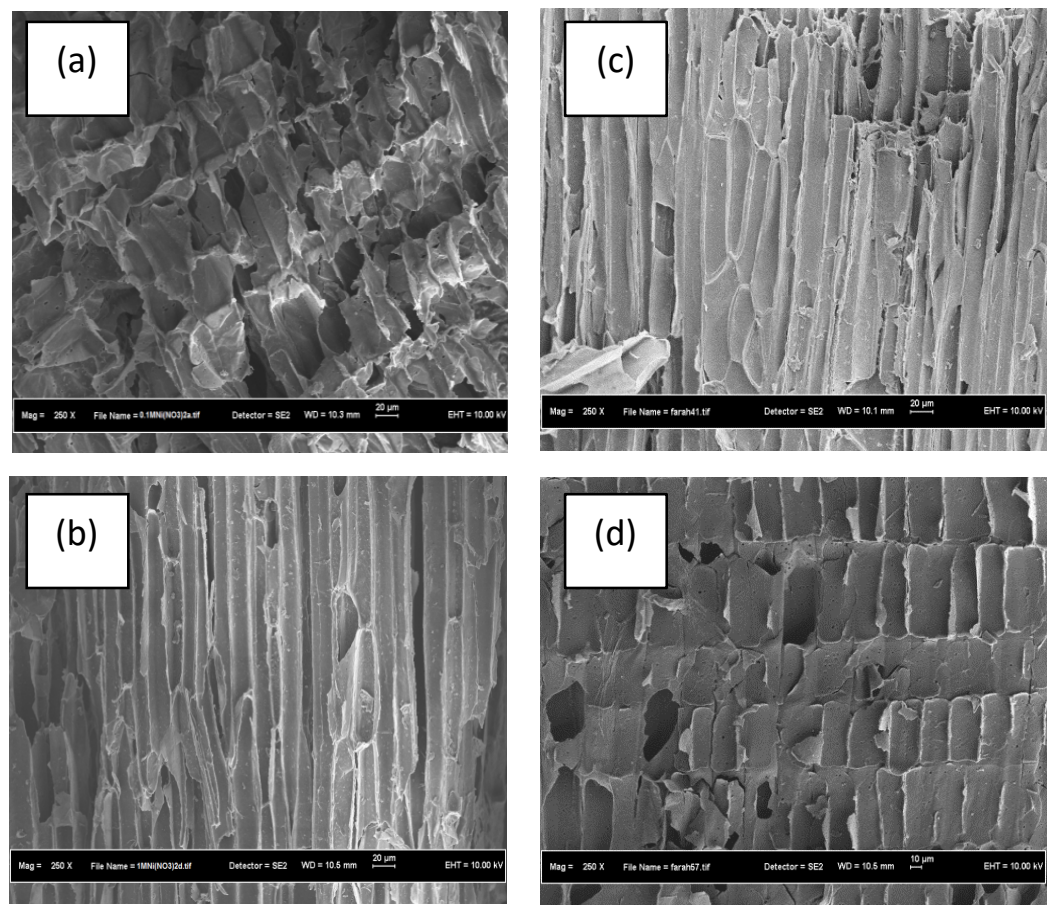

Fig. 3. FESEM images of kenaf modification using (a) $0.03 \mathrm{M}$ nickel, (b) $0.2 \mathrm{M}$ nickel, (c) $0.4 \mathrm{M}$ nickel, and (d) $0.6 \mathrm{M}$ Nickel.

Meanwhile, Figures 3(c) and 3(d) illustrate the surfaces of kenaf modified with $0.4 \mathrm{M}$ and 0.6 M nickel metal, respectively. The physical structures on kenaf modified with $0.2 \mathrm{M}$ and $0.4 \mathrm{M}$ nickel are convincing to be used for adsorptive hydrogen storage in this study. However, with higher concentration of $0.6 \mathrm{M}$ nickel, kenaf surface shows disturbance on its structure. Non-uniform structure on kenaf can possibly disturb storage performance. This has been further discussed in this study.

\subsubsection{Energy dispersive $X$-ray analysis}

EDX analysis was used in this study to determine the chemical characterisation in kenaf samples. For this characterisation, EDX shows an obvious set of chemical peaks contained 
in kenaf and modified kenaf on its X-ray emission spectrum. Figure 4 presents the typical sets of peaks for raw kenaf sample. The existence of potassium $(\mathrm{K})$, calcium $(\mathrm{Ca})$, carbon $(\mathrm{C})$, and oxygen $(\mathrm{O})$ in raw kenaf shows that raw kenaf without modification contains these elements in nature. Meanwhile, gold $(\mathrm{Au})$ existed in this peak because kenaf sample was coated with gold for FESEM analysis.

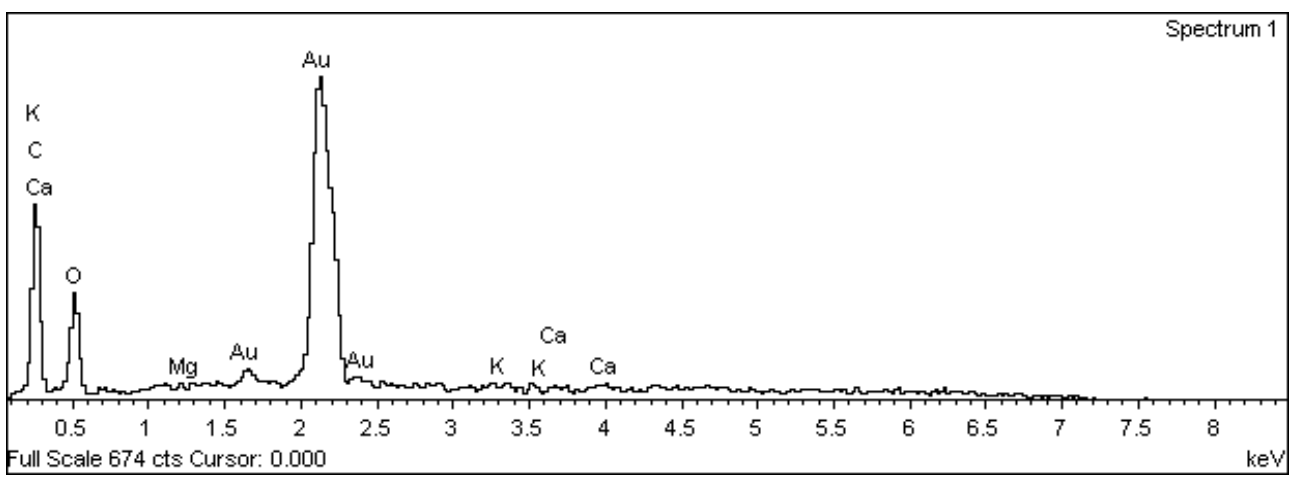

Fig. 4. Energy dispersive X-ray analysis of raw kenaf.

\subsection{Effect of concentration of $\mathrm{Ni}\left(\mathrm{NO}_{3}\right)_{2}$}

Since Ni-metal is suitable for changes in hydrogen adsorption, the concentration of $\mathrm{Ni}\left(\mathrm{NO}_{3}\right)_{2}$ was varied in this study. This is because Ni-metal content in the solution could influence the adsorption capacity onto kenaf surface. Figure 5 shows different hydrogen adsorption capacity using modified kenaf (Ken-0.2MNi, Ken-0.4MNi, and Ken-0.6MNi) at different pressures. Carraro et al. [12] stated that with increasing Ni-metal content, it slightly reduces the value in pore volume. However, they also reported that the highest Ni-metal content increased the oxide particle existence on the surface of the samples. Hence, the structure of samples becomes worse, such as Ken-0.6MNi sample.

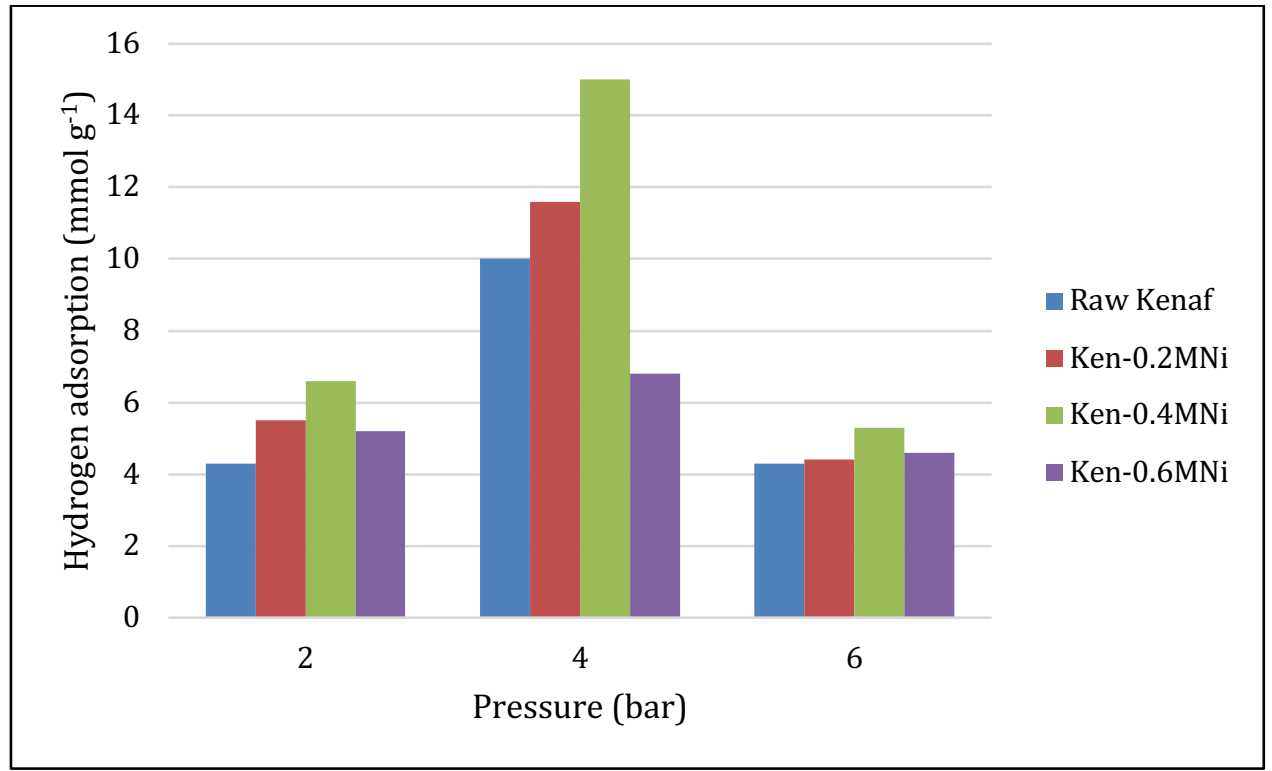

Fig. 5. Hydrogen adsorption capacity using modified kenaf at different concentrations. 
As shown in Figure 5, hydrogen adsorption performance was influenced by nickel loading on modified kenaf at 2 bars. The modified kenaf with nickel loading showed higher ability of adsorbing hydrogen gas onto kenaf as compared to raw kenaf. The hydrogen gas adsorbed onto raw kenaf with $4.3 \mathrm{mmol} \mathrm{g}^{-1}$ kenaf was lower compared to Ken-0.2MNi (5.5 mmol g $\left.{ }^{-1}\right)$, Ken-0.4MNi (6.6 mmol g$\left.{ }^{-1}\right)$, and Ken-0.6MNi $\left(5.2 \mathrm{mmol} \mathrm{g}^{-1}\right)$.

The result shows changes in hydrogen adsorption using modified kenaf compared to raw kenaf. Moreover, the concentration difference increased the active sites, which allowed better interactions between adsorbates and adsorbents. Hence, it leads to higher adsorption capacity of kenaf. However, at higher concentration of $\mathrm{Ni}\left(\mathrm{NO}_{3}\right)_{2}$, Ken- $0.6 \mathrm{MNi}$ was only able to adsorb $5.2 \mathrm{mmol} \mathrm{g}^{-1}$ of hydrogen at 2 bars, $68 \mathrm{mmol} \mathrm{g}^{-1}$ at pressure of 4 bars, and $4.6 \mathrm{mmol} \mathrm{g}^{-1}$ hydrogen at 6 bars due to the excessive amount of modifier that could block or limit the pores in the adsorbent, and thus reduces the adsorption of hydrogen on kenaf porous structure [14].

Different concentrations of $\mathrm{Ni}\left(\mathrm{NO}_{3}\right)_{2}$ obviously show the ability of modified kenaf in adsorbing hydrogen gas. Moreover, Ni-metal contained in the solution plays an important role in adsorbing hydrogen molecules onto kenaf surface. The content of Ni-metal was varied between 0.2 and $0.6 \mathrm{M}$ for this study to investigate the effect of nickel loading onto the kenaf surface and hydrogen adsorption.

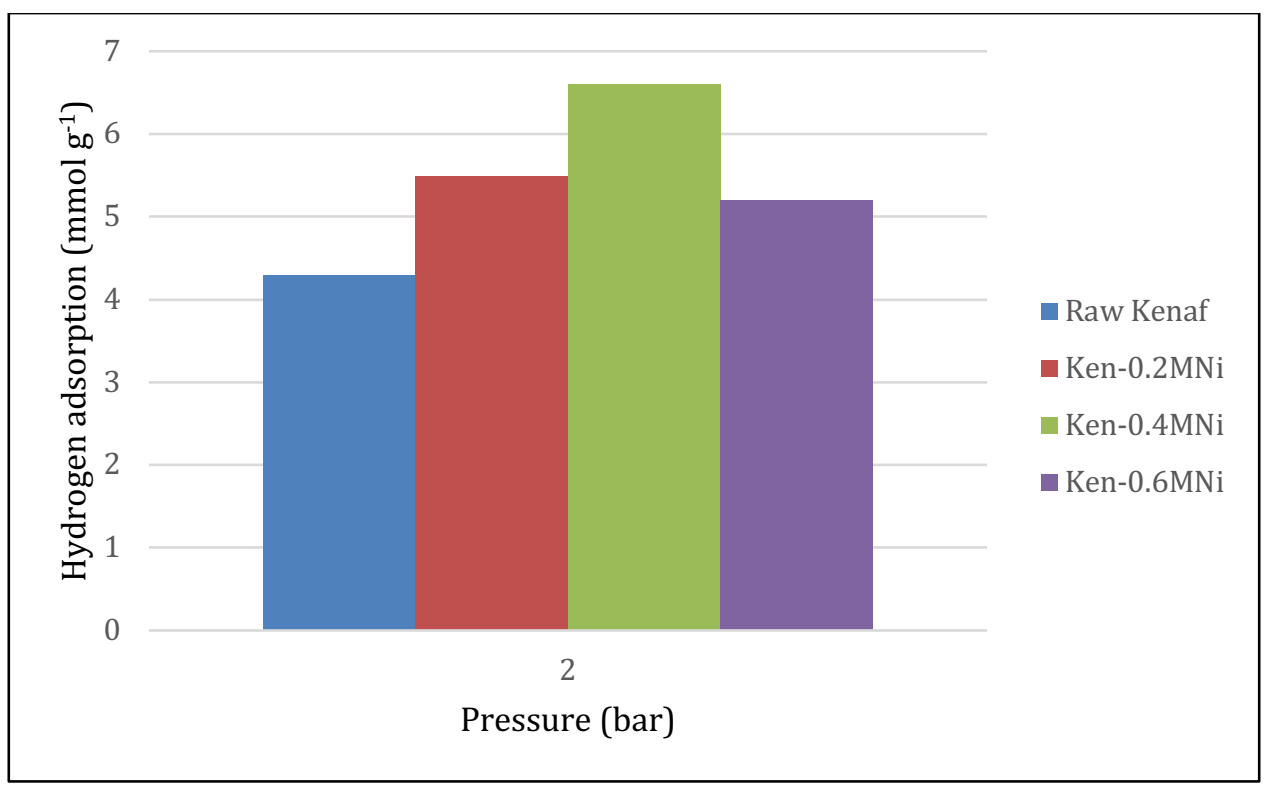

Fig. 6. Hydrogen adsorption performance at 2 bar.

Ken-0.4MNi adsorbent shows a convincing result for hydrogen adsorptive storage. The sample with $0.4 \mathrm{M}$ of Ni-metal loading shows higher hydrogen adsorption capacity compared to $0.2 \mathrm{M}$ of Ni-metal loaded to kenaf sample. This is due to the ability of Ni-metal to adsorb hydrogen gas. By using Ni-metal support, there is a transfer of charges between metal and kenaf surface. Therefore, the positive charge of $\mathrm{Ni}$ atom has polarised the hydrogen molecules on the kenaf surface. However, there are no charge transfer from hydrogen molecules to Ni atom, as the characters are bonded by the charge-induced dipole interaction.

\section{Conclusion}

This study has successfully determined the value of $0.4 \mathrm{M} \mathrm{Ni-metal} \mathrm{concentration} \mathrm{as} \mathrm{the}$ 
optimum value of concentration for modified-kenaf adsorbent. By using the optimum value for the modifier in modified kenaf, it has improved hydrogen adsorption compared to using raw kenaf as an adsorbent. By varying the modifier, the adsorptive capacity of hydrogen has been assessed and the delivery performance of adsorptive hydrogen storage has been achieved.

The authors wish to thank Universiti Teknologi Malaysia for funding this project under Research University Grant Tier 2 (RUG of UTM). Helpful discussions with Prof. Dr. Tomoya Tsuji from Malaysia-Japan International Institute of Technology (MJIIT), Universiti Teknologi Malaysia about hydrogen characteristics and hydrogen materials aspects of this paper are gratefully acknowledged.

\section{References}

1. B. Sakintuna, F. Lamari-Darkrim, M. Hirscher. I. J., Hydrogen Energy. 32, 1121- 1140 (2007).

2. Kidnay A, Hiza M., High Pressure Adsorption Isotherm of Neon, Hydrogen and Helium at 76K., Advances in Cryogenic Engineering 12, 730 (1967).

3. Y.H. Hu and L. Zhang, Hydrogen Storage in Metal-Organic Frameworks, Advanced Energy Materials, 22, 119-120 (2010).

4. C. Gallego, D. Burchell, M. Clark, Carbon Materials for Hydrogen Storage, (2015).

5. E.B. Ogunbode, M.Y. Jamaludin, et al, Potential of Kenaf Fibre in Bio-composite production: A review, Jurnal Teknologi, 77, 10 (2015).

6. Paridah M., Abdelrhman A., Shahwahid M. Cost Benefit Analysis of Kenaf Cultivation for Producing Fiber in Malaysia (2017).

7. Grace Young, Adsorption Surface Phenomenon, Encyclopedia Britannia (2013).

8. N. Zaini, K.S.N. Kamarudin, Adsorption of Carbon Dioxide on Monoethanolamine (MEA)-Impregnated Kenaf Core Fiber by Pressure Swing Adsorption System (PSA), Journal Teknologi, (2014).

9. L. Piccirillo, G. Coppi, Andrew. Miniature Sorption Coolers: Theory and Applications, 3, 68 (2018).

10. Zou et al. Separation and Purification Technology, 161, 39 (2016).

11. N. Farahhin, Kenaf (Hibiscus Cannabinus L.) as Adsorptive Gas Storage Material, (2016).

12. Carraro et al., Microporous and Mesoporous Materials 231, 33 (2016).

13. E. O. Timmermann, Multilayer sorption parameters: BET or GAB values? Colloids and Surfaces A: Physicochem. Eng. Aspects 220, 235-260 (2003).

14. Z. Chowdhury, Preparation, Characterization and Adsorption Studies of Heavy Metals onto Activated Adsorbent Materials Derived from Agricultural Residues (2013). 